\title{
Thoracoscopic Cervicothoracic Sympathectomy for Treatment of Upper Extremity Ischemia
}

\author{
Majid Moini · Mohammad R. Rasouli
}

Published online: 26 March 2008

(C) Société Internationale de Chirurgie 2008

\section{Erratum to: World J Surg}

DOI 10.1007/s00268-007-9293-y

The above-mentioned Letter to the Editor, published online on November 20, 2007, contained an error in the title: the word "Servicothoracic" was used instead of the correct "Cervicothoracic". This article appears in print in the February 2008 issue (volume 32/number 2, pp 331-332).

The online version of the original article can be found under doi: 10.1007/s00268-007-9293-y.

M. Moini $(\bowtie) \cdot$ M. R. Rasouli

Division of Vascular Surgery, Sina Hospital,

Hassan-Abad Square, Tehran 1136933511, Iran

e-mail: moinim@hotmail.com 